\title{
SOME ASPECT OF BRIDGE MANAGEMENT SYSTEMS - INSPECTION, EVALUATION AND MAINTENANCE
}

\author{
RADOMIR Folić ${ }^{1 *}$ AND Doncho PARTOV ${ }^{2}$ \\ ${ }^{1}$ University of Novi Sad, Faculty of Technical Sciences, \\ Department of Civil Engineering and Geodesy, \\ Trg D. Obradovića, 21000 Novi Sad, Serbia, \\ e-mail: folic@uns.ac.rs \\ ${ }^{2}$ University of Structural Engineering and Architecture "L. Karavelov", \\ 175, Suhodolska St., 1373 Sofia, Bulgaria, \\ e-mail: partov@vsu.bg
}

\begin{abstract}
Changes in properties of concrete bridges, during their usage, demand careful monitoring, registration of defects and damage, and corresponding repairs. Therefore, the serviceability mostly depends on the quality of their maintenance. Maintenance of structures is a big problem due to lack of money for repairs. Safety and functionality of concrete road bridges are of a special importance for the traffic flow continuity in different circumstances including after earthquakes, floods, as well as after vessel or vehicle impact on piers. This is why almost all countries use Bridge Management Systems (BMSs). They include the bridge inspection manuals, guidelines, report writing, bridge condition evaluation and determination of priorities (rating) for maintenance work or rehabilitation to achieve the design service life of bridges. This paper presents a comparative analysis of some documents of certain countries and associations, related to BMSs and their main components.

Keywords: concrete bridges, Bridge Management System (BMS), inspections, condition assessment, bridge rating, deterioration, performance, prediction models, service life.
\end{abstract}

\section{INTRODUCTION}

Bridges are the most important component of transportation systems and they play an essential role in the economy. However, bridges are particularly vulnerable elements, especially in case earthquake, impact of ship or/and vehicle in carrying elements and actions of severe environmental conditions. Ac-

${ }^{*}$ Corresponding author.

DOI: 10.7546/EngSci.LVII.20.04.04

Engineering Sciences, LVII, 2020, No. 4 
cording to EN 1990:2002 [1] the desired service life of bridges is 100 years, so it is necessary to secure the cost-effective service of bridges through an adequate design and construction, as well as management. During service life bridge structures may be subject to higher volumes of traffic and higher loads as well as more severe environmental conditions than it was designed. Globally and in the region, Concrete Bridges (CBs) are most common, but their durability is often unsatisfactory. Therefore, the considerations in this paper are focused on them. Their load-bearing capacity and service characteristics degrade over time, so their service life is shorter than expected. They are also influenced by increasing functional requirements and the exposure to the aggressive action of the environment (humidity, temperature and air pollution), and in winter also to de-icing salts. In recent years, the weight and number of vehicles on the roads have been increasing. This necessitates constant monitoring of the condition of bridges, and performing light or intensive maintenance works, in order to enable unhindered traffic flow, provide safe bridges for their citizens. The goal of Structural Management (SM) is to maintain a certain degree of reliability during service life, while optimizing maintenance costs.

Transportation agencies should maintain bridges, a number of which are aging rapidly [2] in acceptable conditions to provide a desirable level of service to the users/public within limited budgets. Department of Transportation (DOT) should provide budget for management business. In many countries comprehensive Bridge Management Systems (BMSs) and bridge inspection practices have been developed. The objectives of a bridge manager are to ensure that bridges achieve their design life, remain open to traffic continuously and keep the risk of failure always very low, achieving this sustainably at a minimum lifecycle cost (BM). Some aspects of bridge management are concerned primarily with the individual bridges (project - level B-M) whereas other aspects are concerned with the management of a stock of bridges (network-level $\mathrm{BM})[3]$.

The role of BMS is of a particular importance in the maintenance cost optimization, for which it is necessary to use a systematic and planned approach based on technical, economic and sociological aspects. They primarily concern the priority, type and scope of intervention measures, as well as the associated costs. Such problems are successfully resolved by the development and application of information systems for managing the structures. Inspections describe different signs of distress in CB, such as leakage, deflection, etc. An inspection can be carried out to indicate the way to maintain a bridge. The objective of Maintenance Inspection (MI) is to detect any defect which may cause an unacceptable safety or serviceability risk. The purpose of a safety in- 
spection is to identify obvious deficiencies which represent, or might lead to, a danger to the public and therefore require special attention and/or immediate or urgent measures.

In recent years, an increasing number of papers have appeared in the world $[4 \div 8]$ in which the experiences of multiple countries are analyzed, especially regarding the method of inspection, and other elements of BMS with the aim of improving their own methodologies based on the experience of others. Among them is [9] which compares foreign experiences with those from the United States, at the state and at the Federal level. This motivated us to write this paper in order to encourage the work on the improvement of BMS in Serbia and Bulgaria, following the example of other countries, and the basis for that are comparative analyses. International associations IABSE, RILEM, fib-international concrete association (formerly CEB and FIP), American Concrete Institute (ACI), American Association of State Highway and Transportation Officials (AASHTO) [10], and others are actively involved in bridge management through recommendations for the design of durable structures, monitoring and condition assessments, scope and timing of maintenance work. This is also provided by the individual States through the Ministry of Transport and/or Transportation agencies. Many of them also develop and prescribe measures for adequate maintenance for bridges in the stage of design to secure their reliability and usability with minimum investment. Important elements also include requirements for durability, accessibility for inspection and suitability for maintenance.

This paper presents some guidelines for inspecting bridges, determining and evaluating their condition, enabling the prioritization and rating of maintenance or rehabilitation activities. Determining the load-bearing capacity of bridges is also important for determining priorities (ratings), so this part and here is partially presented using a deterministic approach, following the example of that used in the United States. One chapter is dedicated to the maintenance of bridges with particular classifications. The development of BMS in Serbia and Bulgaria and the systems applied in some other countries are commented on with a comparative analysis. This paper presents some analyses of the documents related to BMS in Serbia, Bulgaria; South Africa, China, S. Korea, Japan, USA, and some Western Countries (UK, Denmark, Sweden, Germany, et al.). Beside that, a larger fund of literature, Technical regulations (Codes) and Recommendations has been set aside, which directs the reader to the contents that can be used in the work on the management of road concrete bridges. 


\section{REVIEW OF LITERATURE, RECOMMENDATIONS AND CODES}

Due to the importance of the inspection of buildings and their surroundings, all countries have published guidelines with many illustrations. Some guidelines are very extensive, such as Ontario [11], American Association of Highway and Traffic Services [10], some are smaller [12], but they briefly explain the concepts and parts of bridges with guidelines for activities such as the manual used in the UK [13], and also in manuals [14:15]. Review and monitoring have also been considered in $[4,16 \div 18]$ as a federal manual. In [19], several guidelines for the assessment of the condition in service, etc. are included: Guidelines for the repair of concrete superstructures [20]; Routine maintenance of concrete bridges [21]; Causes, evaluation and remediation of cracks in Concrete Structures (CS) [22]; Structural repairs of CS exposed to corrosion and the Manual for protection and maintenance [21], and for repairs $[21,23,24]$ and more in [25].

Aspects of BMS are being considered and introduced in many US states, such as Florida [26], and in other states, including Serbia [27]. In Egypt [28], it is discussed on the bridge management strategy based on the reliability of the semi-Markov deterministic model [29]; in Sabah [4]; in Iran [6]; in Taiwan [8]; in Libya [30]; Symposium in South Africa [31]. In [32], BMS in France and England are presented in comparison, and a broader overview comparing BMS in several countries is analyzed in [33]; European experiences in [34]; and BRIME in [35]; similarly in the paper [36]; The paper [37] is dedicated to the Pontis software, which is mostly used in the USA, and a review of several existing BMS is the subject of the paper [38]. For U.S. states, the Federal Highway Agency (FHA) is in [39], and a broader comparative analysis of U.S. and other state documentation is presented in [39]. Several systems were also compared in [4]. In [2], BMS in Japan, Korea, China, and the United States were critically analyzed, and broader comparative analyzes are the subject of $[5,40]$.

The assessment and methodology developed by the European Commission for Transport Research and Information Monitoring and Information Systems (TRIMIS) are also important. The report critically addresses issues and techniques, and also highlights new technological developments and future-oriented approaches. It includes Italy, Switzerland, Austria, Germany, France, Portugal, Greece, etc. [7]. In some countries, private agencies work on inspection and maintenance at the local level, such as in Ontario, Canada [11]. An overview of the probabilistic design of service life and maintenance is discussed in more detail in $[41 \div 42]$, and with the inclusion of maintenance and life cy- 
cle in $[41,43 \div 50]$. The subject of the paper [51] is a computer platform for the BM integral life cycle. Multi-criteria optimizations for maintenance and rehabilitation works are the subject of $[49,51,52 \div 55]$. Paper [56], related to performance indicator, describes the European COST Action TU 1406 - Quality specifications for roadway bridges, standardization at a European level. Of interest are the publications of the Federation for Concrete for monitoring and evaluation of existing CS [57], for management and maintenance [58, 59] intended for building owners. In [60], a new generation of concrete bridges and tools for its application were considered, as well as in [61]. Concrete bridges condition prediction combines visual inspection and analytical models of deterioration shown in [62]. The probabilistic method of assessment is the subject of papers $[55,63 \div 65]$. Performance indicators were discussed in [56] and economic aspects of preventive maintenance in [66].

Damage to concrete bridges is the subject of the paper [67]. Papers [68 $\div 72]$ are dedicated to the durability and remaining life of bridge structure. It is important to introduce special measures, protection of concrete surfaces and stainless steel reinforcement. In the proposal of the Regulations Model [45, $58,73]$, ISO $[47,74]$ and in papers $[3 \div 4,8,31,75 \div 76]$ mechanisms due to corrosion of reinforcement [77], due to damage to concrete due to the action of frost and de-icing salt were discussed. The frequency of inspections increases with the degree of deterioration and depending on the age and the way the bridge is built [3]. The assessment of bridges in the past, the current state, and the prediction of the future are the subject of the paper [78]. Assessment of the condition, in addition to the cited Manuals and Guidelines, is the subject of papers $[34,36,79 \div 81]$ for the bridge network, in [82] a method of maintenance and rehabilitation was presented with a comparative analysis. Maintenance is dealt with in [83]. The paper [84] is in the same vein. In [85] the broadest problems related to BMS, and the codes related to them are discussed.

In the USA, the realization of BMS is performed in individual states $[11 \div 12$, $16,87 \div 88]$, and at the Federal level according to $[10,18,89]$, and in Germany [90]. Non-destructive testing and sampling are used to assess the condition [17]. Based on the results of these examinations, the scope and type of renovation are decided [39]. The report Monitoring and Information System (TRIMIS) [7] provides a critical analysis with recommendations and techniques while highlighting new technological developments and future-oriented approaches. They have been used in Italy, Switzerland, Austria, Germany, France, Portugal and Greece [7, 52]. It is used in Australia [91], and in [92] a model for predicting the condition of elements used in BMS is described. Development of BMS in Japan, for individual bridges, which is integrated into 
the Miyamoto concrete bridge expert rating system, is given in [93]. Inspection and maintenance of prestressed structures are the subject of [94]. The papers $[80,95 \div 96]$ are dedicated to determining the bearing capacity of existing bridges. Province Trento, Italy, has adopted a bridge management system entirely based on reliability concepts, and includes sections for: condition state evaluation (visual inspections); safety assessment, and prioritization [63].

Figure 1 shows a BMS which contains available data: bridge inventory and "tools", which at the application of adequate models define the strategy of maintenance repair and rehabilitation, and determine appropriate financial needs [10]. The structure of BMS is based on condition rating and Bridge Database (BD), Deterioration Model (DM), Cost Model for evaluation of costs, and Optimization Model for choosing the most rational maintenance strategy. Relationship between bridge condition rating and rate of bridge deterioration with maintenance costs within BMS is very important. Predictions of bridge deterioration are based on the statistical analysis of a large number of data regarding the condition of existing bridges.

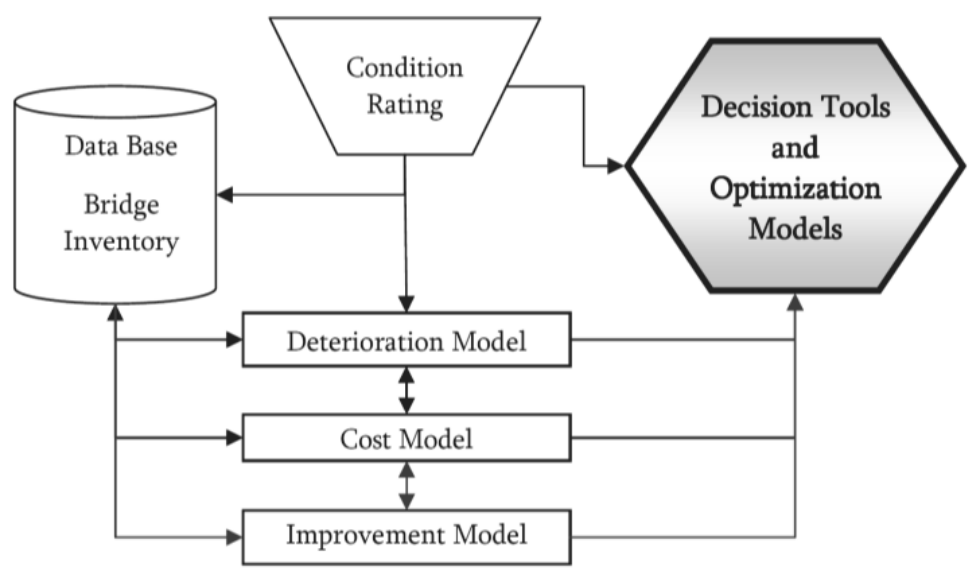

Fig. 1. AASHTO Guidelines for Bridge Management System [83]

\section{HISTORY OF BMS}

In [78] it is stated that in the USA in 2009, there were more than 603,000 bridges recorded. The development of BMS is related to reports of catastrophic collapses such as the famous Silver Bridge on December $15^{\text {th }}$, 1967 with 46 fatalities. This prompted the Federal Agency FHWA to establish the National 
Bridge Inspection Program in 1970. Despite the efforts to inspect the bridges, in June 1983 the Mianus River Bridge on the I-95 collapsed, killing three people. This disaster caused concerns regarding fatigue and fracture-critical bridges. The program mandated that bridges be inspected at least once every two years and an Inventory of the Bridges is formed. In the 1990s, the wellknown software packages PONTIS and BRIDGIT in the USA and DANBRO in Denmark were developed.

Sweden has the longest experience with management (since 1940), contributing to a reduced allocation for maintenance, as a fraction of the value of construction. In Serbia, the Public Road Company published a translation of their Sweden Bridge Inspection Manual in 2009, but it was not incorporated into the overall BMS. Determining the load-bearing capacity of bridges is also important for forming priorities (range). A deterministic approach modelled on the one used in the United States [5] is recommended. This methodology is briefly presented in the chapter Evaluating Bridges of this paper.

A comparative overview of the BMS of several European countries, including Serbia and Bulgaria, is presented in Table 1 according to [97]. The table contains data on the beginning of the introduction of BMS. This occurred in Serbia in 1985 and in Bulgaria in 2004/2005. A system of prioritization was introduced in Serbia, while in Bulgaria it was not, until 2009. The number of bridges included in BMS in Serbia is 3500, and in Bulgaria it is 1312. Scan point-Freissinet software is used in Bulgaria, and BPM in Serbia. Although the implementation of BMS started relatively early in Serbia, a unified system has not yet been constituted.

The Bridge Inspection Manual used in Sweden was translated in Serbia 2009 but has not been officially adopted for implementation. There were also negotiations with France but without results. Bulgaria uses French software. Other European countries are also developing the system and lag behind the United States. One chapter in [14] is dedicated to BMS and bridge evaluation in Serbia. Regulations (1992) cover technical standards for utilization and regular maintenance of bridges. They include the following: contents of the data to be registered (data bank); kinds of inspections (control, regular, main and extraordinary), as well as their contents regarding the elements of bridges; specification of works on regular maintenance. Maintenance considers inspection, observation and recording of changes and their condition, maintenance activities and measures for eliminating all defects and damage. The following types of inspections are performed according to the Yugoslav Regulation 1992 [27], cited in [5]: control inspections; regular inspections; detailed inspections; special inspections, and extraordinary inspections. 
Table 1. BMS in European country, after [97]

\begin{tabular}{|c|c|c|c|c|}
\hline Country & $\begin{array}{c}\text { Year of BMS } \\
\text { starting }\end{array}$ & $\begin{array}{c}\text { Prioritization } \\
\text { in BMS }\end{array}$ & $\begin{array}{c}\text { Number of } \\
\text { bridge managed } \\
\text { in BMS }\end{array}$ & $\begin{array}{c}\text { Used } \\
\text { system/software }\end{array}$ \\
\hline Bulgaria & From 2004/5 & No & 1312 & $\begin{array}{c}\text { Scan print- } \\
\text { Freissinet }\end{array}$ \\
\hline Croatia & $\begin{array}{c}\text { Developed } \\
\text { now }\end{array}$ & Yes & $\begin{array}{c}800 \text { on } \\
\text { motorways }\end{array}$ & Oracie 10.G \\
\hline $\begin{array}{c}\text { Czech } \\
\text { Republic }\end{array}$ & 2002 & Yes & 18740 & $\begin{array}{c}\text { IIS database+ } \\
\text { MS SQL Server }\end{array}$ \\
\hline England & 2001 & Yes & 8600 & Oracle \\
\hline Estonia & 2001 & Yes & 922 & Pontis \\
\hline France & 1999 & Not yet & 9000 & Own system \\
\hline Germany & $2000 / 2001$ & Yes & 38000 & $\begin{array}{c}\text { SIB-Bauwerke; } \\
\text { BMS-Optimisation- } \\
\text { tools }\end{array}$ \\
\hline Hungary & 1996 & Yes & 6000 & Own system \\
\hline Italy & 1986 & Yes & 3626 & $\begin{array}{c}\text { Oracle, } \\
\text { SQL Server }\end{array}$ \\
\hline Latvia & 2002 & Yes & 1775 & LatBruts \\
\hline Serbia & 1985 & Yes & 3500 & BPM \\
\hline
\end{tabular}

In Serbia, there has been active work on the introduction of BMS, with IT aspects of the database since 2001, and a single BMS in Serbia has not yet been constituted. The Road Information System (RIS) contained a database (BP) on bridges and a BP on traffic. In GIS, along with data on space and location of structures with their environment are stored, edited and purposefully used. The Integrated Road System had the following structure: inventory data on the bridge; data on inspections of bridges (bridge condition, bridge rating, and element condition category, bearing capacity data); data on emergency transport; and planned and performed works. The BMS was created at the Roads Institute, after the model of the bridge management system in the USA and the Organization of Economics Cooperation and Development (OECD) by the late D. Bebić [98]. A bridge database started to gradually progress towards assessing the load-bearing capacity of bridges [5]. Its multi-disciplinary character was prominent. The described BMS requires its further elaboration by introducing financial indices which would enable the owner to plan the funds for maintenance, a system of evaluating the condition of bridges in connection with rehabilitation works, evaluation criteria used for the determination of structural and functional bridge adequacy. Technical regulations for the 
bridge structure maintenance existed until 1992. In cases requiring revitalization measures of bridges, optimum solutions are obtained on the basis of research works, in line with a special procedure.

Recent researches and surveys provide a picture of the state of BMS in many countries in the world, which can be seen from the data shown in Table 2. From them, the intervals for inspecting bridges can be compared.

Table 2. BMS in another country, after [99]

\begin{tabular}{|c|c|c|c|}
\hline $\begin{array}{l}\text { Country; No. } \\
\text { of bridges }\end{array}$ & $\begin{array}{l}\text { Type } \\
\text { of inspection }\end{array}$ & $\begin{array}{l}\text { Contents } \\
\text { of activities }\end{array}$ & $\begin{array}{l}\text { Intervals } \\
\text { of activities }\end{array}$ \\
\hline \multirow{2}{*}{$\begin{array}{l}\text { Argentina } \\
3,418 \\
\text { bridges }\end{array}$} & Ordinary & $\begin{array}{l}\text { Survey of } \\
\text { expedition }\end{array}$ & Annual \\
\hline & Main & $\begin{array}{l}\text { Detailed-special } \\
\text { equipment }\end{array}$ & \\
\hline \multirow{3}{*}{$\begin{array}{l}\text { Canada- } \\
\text { Quebec } \\
9,600 \\
\text { bridges }\end{array}$} & Annual & $\begin{array}{l}\text { Visual inspection } \\
\text { without specialized } \\
\text { equipment }\end{array}$ & Annual \\
\hline & General & & \\
\hline & Underwater & & \\
\hline \multirow{3}{*}{$\begin{array}{l}\text { Denmark } \\
2,000 \\
\text { bridges }\end{array}$} & Principle (PI) & $\begin{array}{l}\text { Through visual } \\
\text { inspection }\end{array}$ & \\
\hline & 6 years & & \\
\hline & Special inspection & & $\begin{array}{l}\text { If special problems } \\
\text { detected during PI }\end{array}$ \\
\hline \multirow{3}{*}{$\begin{array}{l}\text { Japan } \\
12,393 \\
\text { bridges }\end{array}$} & Daily patrol & & Daily \\
\hline & Routine/Visual & & 5 years \\
\hline & Special & & $\begin{array}{l}\text { If special problems } \\
\text { are detected }\end{array}$ \\
\hline \multirow{2}{*}{$\begin{array}{l}\text { Korea } \\
8,267 \\
\text { bridges }\end{array}$} & Routine & & $\begin{array}{l}\text { Depend of bridge condition } \\
\text { A-C } 6 \text { months; D,E } 1 \text { month }\end{array}$ \\
\hline & $\begin{array}{l}\text { Precision checking } \\
\text { In-depth }\end{array}$ & & $\begin{array}{l}\text { Depend of bridge condition } \\
\text { A: } 3 \text { years; B, C } 2 \text { years; } \\
\text { D } 1 \text { year }\end{array}$ \\
\hline \multirow{2}{*}{ Mexico } & Routine & & Twice a month \\
\hline & $\begin{array}{l}\text { On-site } \\
\text { engineering }\end{array}$ & & Once or twice a year \\
\hline \multirow{2}{*}{ Slovenia } & Routine & & Twice or twice a year \\
\hline & Main & & Every 5 years \\
\hline \multirow{2}{*}{$\begin{array}{l}\text { Spain, } \\
10,500 \\
\text { bridges }\end{array}$} & Routine & & Once a year \\
\hline & Principal & & 5 years \\
\hline
\end{tabular}

Engineering Sciences, LVII, 2020, No. 4 
Table 2. BMS in another country, after [99], continuation

\begin{tabular}{|c|c|c|c|}
\hline $\begin{array}{l}\text { Country; No. } \\
\text { of bridges }\end{array}$ & $\begin{array}{l}\text { Type } \\
\text { of inspection }\end{array}$ & $\begin{array}{l}\text { Contents } \\
\text { of activities }\end{array}$ & $\begin{array}{l}\text { Intervals } \\
\text { of activities }\end{array}$ \\
\hline \multirow{4}{*}{$\begin{array}{l}\text { Switzerland } \\
3,500 \\
\text { bridges }\end{array}$} & Surveillance & & Once every year \\
\hline & Main & & Once 5 years \\
\hline & Intermediate & & $\begin{array}{l}\text { For determinate } \\
\text { bridges }\end{array}$ \\
\hline & Special & & $\begin{array}{l}\text { Under. After } \\
\text { extraord. Events }\end{array}$ \\
\hline \multirow{6}{*}{$\begin{array}{l}\text { USA - } \\
\text { FHWA* } \\
607,000 \\
\text { bridges }\end{array}$} & Routine & Regularity scheduled & Not exceed 2 years \\
\hline & Underwater & $\begin{array}{l}\text { Inspect underwater } \\
\text { part }\end{array}$ & Not exceed 5 years \\
\hline & Fracture critical & Hands on & Not exceed 2 years \\
\hline & Damage & From environmental & As needed \\
\hline & In - depth & Close-up inspection & As needed \\
\hline & Special & To monitor deficiency & As needed \\
\hline \multirow{8}{*}{$\begin{array}{l}\text { USA - } \\
\text { Wisconsin }\end{array}$} & Routine/Visual & FHWA Mandate & 2 years \\
\hline & Damage & FHWA Mandate & As needed \\
\hline & $\begin{array}{l}\text { Routine/ } \\
\text { Load Posted }\end{array}$ & State mandate & 1 year \\
\hline & In-depth & FHWA Mandate & 6 years \\
\hline & Fracture critical & FHWA Mandate & 2 years \\
\hline & Underwater survey & FHWA Mandate & 2 years \\
\hline & Underwater diving & FHWA Mandate & 5 years \\
\hline & $\begin{array}{l}\text { Underwater } \\
\text { Probe/vis }\end{array}$ & State mandate & 2 years \\
\hline
\end{tabular}

Argentina-Ordinary-Annual; Main with detailed survey 3 years, and special upon request. England-General 2 years, and Principal 6 years, etc.

Report [99] deals with bridge inspection practice, estimation of load carrying capacity, and traffic restriction. Information is based on the answers from 18 road authorities in 16 countries. Traffic restriction methods currently applied are mainly methodologies: bridge closure, limit the number of traffic lanes, and limit the maximum tonnage of track axles or in total of a truck. The most important measure is quick repair to avoid traffic restrictions for all countries.

\section{DURABILITY AND REMAINING SERVICE LIFE}

The causes of degradation are classified as objective: (traffic and environment); temperature, alternating freezing and thawing and temperature gradient; chemicals (primarily chlorides near the sea or due to the application of 
de-icing salts); and subjective: properties of the element, structure and their maintenance; the quality of the concrete in the protective layer; insufficient longitudinal and/or transverse slope of the road, inadequate drainage system, waterproofing, expansion joints, etc.

However, water is the most common cause of deterioration of elements and structures. Therefore, it is of special importance to manage water using adequate drainage. This is achieved by providing a sufficient longitudinal and transverse slope of the road. Good quality waterproofing, drains, expansion joints and railing anchoring points are important, as well as cleaning of drains and drainage channels. Other causes of damage are: earthquake; moving (sliding) of the ground; flood waves; scouring, tidal action; aggressive substances in air and water.

A simplified model for determination of durability of building structure introduces dependence of reliability parameters (load-bearing capacity, deformations etc.), depending on time $t$. In the deterministic approach to design, the values of action $S$, load-bearing capacity (resistance) $R$, and service life are considered as determined values - they do not depend on time, so the distribution of these values is not considered. In essence, these values are time-dependent, so the following expression should be used:

$$
R\left(t_{g}\right)-S\left(t_{g}\right)>0,
$$

where $t_{g}$ is the target service life, so the service life is determined by the expression $t_{L}-t_{g}>0$; whereby $t_{L}$ is the service life function. It was considered in more detail in $[45 \div 46,59,68 \div 69,72]$.

The measures for increasing durability and for damage reduction on the bridge which are implemented in various phases [5] are:

- Such a choice of the form of elements and drainage systems which would provide the road water drainage in the shortest and fastest manner;

- Good quality waterproofing and the wearing course;

- Proper choice and installation of bridge equipment, especially of the drainage system, expansion joints and railing;

- Regular inspections and bridge maintenance. Regular cleaning of drainage channels, discharge pipes and expansion joint is of particular importance;

- Control of crossing of extraordinary, i.e. outsized loads across the bridge.

Determination of the remaining service life, according to [42] is shown in Fig. 2.

Engineering Sciences, LVII, 2020, No. 4 


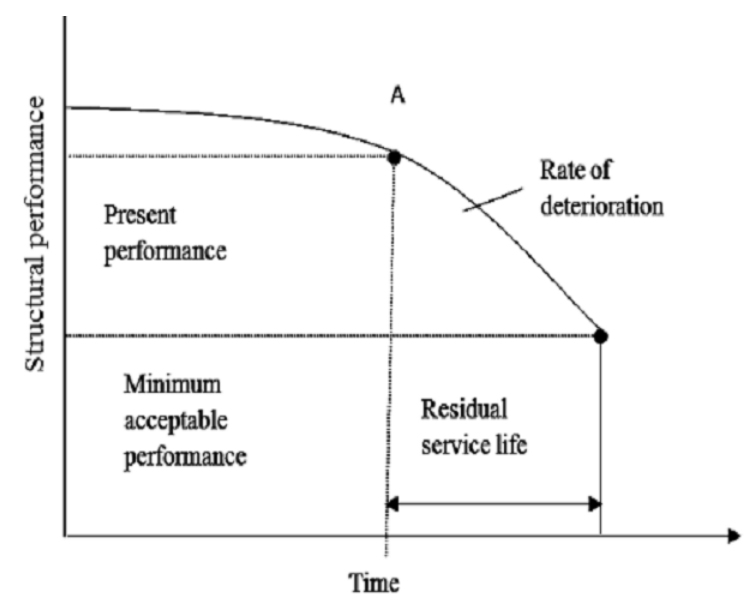

Fig. 2. Determination of the remaining service life, according to [42] (first columns hither: actual performance - upper, minimum acceptable performance, lower right remaining service life)

\section{REQUIREMENTS FOR BMSs}

BMS should contain the following [10, 14, 100]:

- Registration and description of individual structures and their actual condition. The recorded and estimated data obtained during inspection are used for this;

- Bridge assessment in terms of traffic safety - functionality, stability, durability and maintainability;

- Assessment of their future behaviour due to ageing and adverse actions, especially the model for deterioration prediction;

- Feedback on strategies and maintenance design;

- Guidelines of the strategy for maintenance works;

- Budget allocation to various structures;

- Proper execution of these strategies;

- Bridge replacement strategies.

Developing a custom-made BMS is a long-term commitment involving initial investment, life-cycle maintenance costs, and state-of-the-art expertise. Information Management Systems (IMSs) require periodic upgrades. Maintenance is evaluated according to the following three types of standards [85]:

1. Quality standards, describing the results to be achieved;

2. Quantity standards, identifying the amount of work and resources necessary to meet the quality standard or a predetermined level of service;

3. Performance standards, describing a general method of performing a task, the resources required, and the rate at which the work should be performed. California Department of Transportation comments can be found in [85]. 
BMS includes regulations, standards, normative documents and all technical and organizational measures related to the traffic and other aspects of management. In order to implement this approach a user should possess a high quality information system, i.e. computer database on the operation and maintenance of the system, and networks. Real processes, human resources, technology and financing are all important for realization. Computer system - central database:

- Database on the bridges in the network;

- Organization of work and financing, network and maintenance system management - organization and regulations;

- Technical aspect - financial and organizational aspects;

- Relation Condition-Budget-Interventions. Timeline and dynamics.

In many countries, as well as in our region, questions are being asked:

- What is the real condition of bridges and is the BMS being used adequate or should it be improved?

- How much does it cost to bring the existing old bridges to the state of acceptable performance?

- Are adequate datasets provided for adequate and optimal interventions on the bridges?

Management and maintenance require systematic monitoring - the monitoring of BMS should enable organized data collection for analysis and assessment at all stages of the life cycle depending on the importance of the road and the complexity of the structure. The United States are the leaders in this area. BMS should be focused on the existing bridges with a goal to ensure the realization of their designed service life, i.e. to keep them continuously open for traffic, and minimize the risk of "failure" [19]. The term bridge management comprises a wide range of activities, primarily monitoring-inspections, assessments of future condition through models of deterioration over time to determine priorities for performing maintenance work. The load-bearing capacity of the bridge, especially under oversized loads should be determined, and various tests should be performed. These activities should result in a more cost-effective maintenance of the bridges and the environment.

In the USA, the realization of BMS is being worked on both in individual states and at the Federal level [9]. Management usually includes a set of bridges in the traffic network, and less often individual bridges, and one of the primary tasks is to evaluate their condition and rate of deterioration. It is important to provide quality designs and their realization of service life and provide its realistic prediction $[4,78]$. Due to limited funds, the mentioned priorities for the realization of works should be determined and observed. In

Engineering Sciences, LVII, 2020, No. 4 
order to achieve that, it is necessary to determine the actual condition of the construction by a set of inspections that are regularly performed at regular intervals. BMSs always set the condition that the review procedures be standardized, in order to be uniform and objective, because they are performed by experts with different levels of knowledge and criteria. Adequate questionnaires, neither too extensive nor incomplete, provide a faster, cheaper and more realistic overview. Increasingly, bridge life cycle planning is being introduced, which includes costs from design, construction, and management to demolition of the structure. Life cycle management is based on cost-effectiveness while exploring the possibilities of optimizing factors such as cost, profit, risk and quality, durability, sustainability, etc. [5]. Quality Management (QM) is a comprehensive approach to all phases since the creation of a structure to its replacement $[78,58]$. In the papers $[101,102]$, the application of modern information Building Information Modelling (BIM) technology in BMS is also recommended.

The consideration of BMS is inseparable from the durability of bridge structures whose exposure to adverse environmental impacts is pronounced [10]. Bridge maintenance is a set of all measures and procedures that are taken during the service life in order to achieve the required durability with the achieved level of safety and serviceability [5]. In doing so, bridge inspection manuals/guidelines are used to inspect bridges, often official documents of individual countries. In addition to the textual part, the graphic illustrations show the characteristic parts of the bridge structure, equipment and the immediate surroundings of the bridge [13]. Some papers compare the deterministic and probabilistic approach to management [65]. It is also important to predict the future condition of the bridge, using a deterioration model, in order to optimize costs. Most of our professionals rely only on Eurocodes (EN), although the documents [59] are more up-to-date.

Assessments are performed using the methodology developed by the European Commission for Transport Research and Information Monitoring and Information Systems [96]. The report performs a critical analysis with recommendations and techniques while highlighting new technological developments and future-oriented approaches. They have been used in Italy, Switzerland, Austria, Germany, France, Portugal and Greece [6]; On the reliability management strategy of bridges based on reliability Semi-Markov deterministic model [13]; in Sabah [4]; in Iran [6]; in Italy [36], in Japan [103], and in UK [104]. European experiences and BRIME are presented in [35]. For the states in the United States, the Federal Highway Agency presented a comparative analysis in [18]. An overview of probabilistic design of service life and maintenance 
is discussed in more detail in [65]. It is assumed that the service life of the structure is determined by design and construction, but also by its management. The mathematical performance model involves an aging process similar to modelling in structural design.

\section{INSPECTIONS IN CODES AND PRACTICE}

The inspection is performed by the experienced professionals familiar with the theory of structures and with experience in designing, building or maintenance of bridges. According to [87] four years of experience in inspections is required and the leader should have five years or successfully completed FHWA-approved comprehensive bridge inspection training course. Prior to performing the inspection, the engineers should study the documentation and compile a list of equipment used during the inspection, the method of sampling and potential testing. During the inspection, defects and damages are registered with an assessment of their causes and the condition of the bridge elements and materials. In doing so, well-established terminology should be used to rule out misunderstandings. Their findings are entered in the cadastre for the purpose of comparison with the previously determined situation. Corrosion of concrete and reinforcement, disconnection of individual parts of the structure are recorded separately.

Due to the importance of inspecting structures and their surroundings, all the states have published guidelines with many illustrations. Some guidelines are very extensive, such as Ontario [11], and some smaller ones are concisely explained terms and parts of bridges with guidelines for activities [5, 3] as a federal handbook [10]. In [10], several documents were included, including guidelines for assessing the condition in operation and routine maintenance of bridges. The main goal of the inspection of the bridge and its components is to register defects and damages that affect safety and usability and/or reduce their service life by increasing the degree of deterioration. There are general, main and special examinations in the UK. General ones are performed every other year, and are based on visual inspection from accessible positions using binoculars and artificial lighting [13].

General inspection must provide information on the physical condition of all visible elements and comprise a visual inspection of all parts without special access equipment or traffic management arrangements. Principal inspection must provide comprehensive and detailed information on the physical condition of all inspectable parts of a highway structure. Inspection techniques include hammer tapping to detect elimination of concrete cover (six-year in- 
tervals). Special inspections for structures with weight restrictions, before and after having to carry abnormal heavy load, if settlement is greater than allowed for or structures subjected to accidental damage, river bridge after flooding (underwater inspection). Inspection for assessment includes parameters needed to determine the strength of members including possible deficiencies (cracks, corrosion, settlement, defective material, drainage system, etc.). Scheduling of inspection, preparation for it, records (location, severity, extent and type of defects and damage) needed to carry out a structural assessment. Access for inspection may be by ladder, scaffolds, mobile elevating work platform, vehicles with a hydraulic operated walkway. Signs of distress in RC (defects and damage of RC beams and slabs, cracks) must be registered. Profile of bridge deck may need to be checked for sagging or unusual deflection [3].

In Serbia monitoring of concrete bridges was prescribed in 1992, and afterwards the Regulation on the roads of 1993. The activities important for BMS are prescribed in them. The aim of regular inspections is to control the state of a structure directly and keep the traffic safety on a satisfactory level. Control inspections are done by a road inspector, at least once a month. Due to that, in addition to monitoring of deficiencies in due time, it is necessary to study all available documentation in order to define, in the first place, the causes of occurrence of the damage. It begins with an initial visual inspection which is meant to obtain data concerning scope and way of detailed inspection. Primarily, it is necessary to provide a safe access to the damaged structure. On the basis of the visual inspection the scope of detailed inspection and testing methods are determined [75].

A detailed inspection is aimed to obtain information on an optimal scope in order to assess the condition of structure and possibility of further use with necessary interventions. Detailed inspections of bridges should be done at last once in two years. During the inspection all elements of the bridge are included. During special inspections, special equipment and measuring instruments are used in order to check the actual degree of damage, especially at structures for which it has been established, by the regular or occasional inspection, to be at risk of falling down or ruining, which requires urgent repairs. A special inspection is conducted according to a previously planned program. Extraordinary inspections are conducted according to the regular inspection rules after an unexpected event, as well as before and after the transportation of an extraordinary load which might endanger the capacity or function of the structure. In the case of damage, equipment for the inspection is the same as during the special inspection [72]. 
Inspection types are: inventory (Initial) inspection; routine inspection; indepth inspection; fracture critical inspection (steel member) - fatigue is primary cause of failure; underwater inspection; special inspection; damage inspection with damage assessment. A routine bridge inspection consists of visual observations and/or measurements that are to determine following:

- The physical and functional conditions of bridge;

- Change from initial or previously recorded conditions;

- Repair or other services that may be needed.

The purpose of an in-depth inspection is to assess bridge elements that are not accessible. This inspection may involve testing, monitoring, or conducting specific analysis of select bridge elements. Inspection is typically performed: to obtain more sophisticated data; to perform special testing; to bring in experts to assess a particular problem. This type of inspection can be scheduled independent of a Routine inspection at longer intervals, and may also include a load rating to assess the residual capacity of members depending on the extent of the deterioration or damage. A special inspection is scheduled at the discretion of a bridge or the responsible agency [87].

\section{EVALUATION OF BRIDGE CONDITION}

Condition evaluations are designed to produce results within an anticipated range. Assessments and their predictions focus on specific aspects of the overall condition, such as the degradation of materials, the deterioration of structural elements, and the entire structures [85]. All bridge condition ratings combine deterministic and probabilistic methods as well as top-down and bottom-up approaches. NBI sufficiency rating evaluates bridges in their entirety.

It is important to predict the type of degradation process of individual elements. Statistic data processing of monitoring of similar structures behaviour can be useful. The BRIME [63, 85] report defined the scope of the task as follows: "Deterioration models describe the slow degradation and change in strength of a material and are used to predict the change in structural as well as functional parameters due to the accumulated levels of structural loading, environmental conditions, and maintenance practices". Also they classify models into three categories that are not necessarily mutually exclusive, namely: deterministic; stochastic; and artificial intelligence. Deterioration Models can be based on statistical (stochastic) or physical (phenomenological) interpretation of the data. Statistical and physical considerations are often combined deterministically. The Markov chain model is chosen as the predicting tool of BMS packages deterministically $[29,85]$. Physical properties are no longer assigned 
for fixed values deterministically, but are modelled as probability distributions.

The guide ACI 345 [21] provides satisfactory performance and remains in service for many years. Neglecting or delaying bridge maintenance may result in a reduced service life and increased costs due to repair, rehabilitation, or replacement at an early age. Contrast, continuous and systematic maintenance of a bridge will extend its service life and reduce its overall operation cost. Maintenance is defined as those activities that are relatively inexpensive and repeatable, performed when a structural member is still in good condition, intended to prevent or minimize its deterioration and prolong functionality of the bridge.

Based on the periodical or special inspections, damage is systematized in five classes:

1. Severe damage requiring urgent repairs.

2. Damage requiring repairs in near future.

3. Slight - initial damage which should be registered and monitored.

4. Light damage which does not require monitoring.

When a condition of a structure is considered, a number of criteria can be introduced, such as safety and/or durability of elements, serviceability of the structure and of its elements etc. Yet, a number of properties unified under the term of reliability must be analyzed. One important property is maintainability which is the accessibility/suitability of the element or structure to provide detection and removal of defects and damage and prevent errors in maintenance works. This property includes the availability of adequate maintenance organization, and restoring the component or structure back in operational order within the planned downtime.

The inspection system, which includes a visual inspection, is prescribed by the BRIME standard and the Italian code. This inspection can be undertaken by the road maintenance staff to ascertain their condition, without special equipment, only by visual inspections [36]. The Evaluation of the condition based on the UK experience introduced a condition value which varies from 1 to 5 , and corresponds to the condition of the related precise group of defect of the element, Table 3 . The bridge structure can be divided into its fundamental components (for the structural capacity and safety against collapse) and nonstructural elements relevant for functionality and durability of the structure. A different weight $\mathrm{W}$ assigned to each elements varies from 10 (maximum importance) to 5 (minimum importance).

A Location Factor (LF) corresponds to each weight, as shown in Table 4. The Road Directorate of Denmark collects Condition Ratings (CR) for 13 bridge components: entire structure; wing walls; slopes; abutments; in- 
termediate supports; bearings; load-carrying superstructure; water-proofing; end beams; safety barrier; surfacing; expansion joints; and other components. The overall rating scale is 0 to 5 , with " 0 " meaning no damage and " 5 " that the components can no longer function. Bridge components are identified in a hierarchical numbering system that allows inspectors to assign conditions and record observations about general regions of the bridges (deck, superstructure, and substructure). Norwegian practice reports condition ratings for bridge element and identifies specific types of damage that are observed.

Condition ratings are reported on a 1 to 4 scale, with 1 indicating good condition. CR are provided for each four consequences of element condition: strength, traffic safety, maintenance cost and aesthetics. French practice reports $\mathrm{CR}$ on a 1 to 3 scale. Range 2 and 3 are subdivided according to the urgency of maintenance/intervention. In Germany CR scales run from 0 (good) to 4 (very poor). Each bridge component is assigned three ratings: one each for structural damage, traffic safety, and bridge durability [9]. Many documents point out that more durable structures have a longer service life and are much easier and cheaper to maintain [105].

Table 3. Condition value (CV), after [35]

\begin{tabular}{|l|c|c|}
\hline Defects & CV & $\begin{array}{c}\text { Conversion from the CV } \\
\text { to the Condition Factor (CF) }\end{array}$ \\
\hline No judgement & 0 & 0 \\
\hline No meaningful defect & 1 & 10 \\
\hline Minor defects that do not cause damage & 2 & 7 \\
\hline Moderate defects that could cause damage & 3 & 4 \\
\hline Severe defects that cause damage & 4 & 2 \\
\hline Non-functional or non-existent element & 5 & 1 \\
\hline
\end{tabular}

Table 4. Location Factor (LF) and weight (W), after [36]

\begin{tabular}{|l|c|c|}
\hline Structural elements & LF & W \\
\hline Principal elements (beams, arches, piers) & 5 & 10 \\
\hline Transversal elements (bearing, non-seismic devices, slabs) & 6 & 9 \\
\hline Abutments, approach embankment, wing-walls & 7 & 8 \\
\hline Abutment and pier foundations & 8 & 7 \\
\hline Non-structural elements & LF & W \\
\hline Waterproofing, road pavement, expansion joints & 9 & 6 \\
\hline Pavements, parapets, drainage systems, accessories & 10 & 5 \\
\hline
\end{tabular}

Engineering Sciences, LVII, 2020, No. 4 
The method of assessing the condition of bridges and their components is important. Table 5 shows the methodology of assessing the condition in Japan, by connection the condition and describing the actions.

The bridge inspection report forum is created for initial inspection of determination of the baseline of every bridge condition by using general condition rating Table 6 which was established by FHWA [18]. Performance indicators for bridge quality control and management are shown in [56].

Table 5. Bridge soundness (MLIT, 2014) Japan [2]

\begin{tabular}{|l|l|}
\hline Condition & Description \\
\hline 1. Good & No problems in bridges functions \\
\hline 2. Preventive maintenance & $\begin{array}{l}\text { No problems in bridges functions but preventive } \\
\text { maintenance required }\end{array}$ \\
\hline 3. Early action & $\begin{array}{l}\text { Possibility of problems in bridges functions, need for } \\
\text { early actions }\end{array}$ \\
\hline 4. Emergency actions & $\begin{array}{l}\text { Possibility of problems or existing problems in } \\
\text { bridges functions, need for emergency action }\end{array}$ \\
\hline
\end{tabular}

Table 6. NBI Condition ratings FHWA [18]

\begin{tabular}{|c|l|}
\hline Rating & Description \\
\hline 9 & Excellent conditions. \\
\hline 8 & Very good conditions. No problems noted. \\
\hline 7 & Good conditions problems noted. Some minor problems. \\
\hline 5 & $\begin{array}{l}\text { Satisfactory conditions. Structural elements show some minor deterio- } \\
\text { ration. }\end{array}$ \\
\hline 4 & $\begin{array}{l}\text { Fair foundation. All primary structural elements are sound but may } \\
\text { have minor section loss, cracking, spalling, or scour. }\end{array}$ \\
\hline 3 & $\begin{array}{l}\text { Critical conditions. Loos of sections loos, deterioration spalling, or scour. } \\
\text { structural elements. Fatigue cracks in steel or shear cracks in concrete } \\
\text { may be present. }\end{array}$ \\
\hline 2 & $\begin{array}{l}\text { Critical conditions. Advanced deterioration of primary structural ele- } \\
\text { ments. Fatigue cracks in steel shear cracks in concrete may be present } \\
\text { or scour may have removed substructure support. Unless monitored, it } \\
\text { may be necessary to close the bridge until corrective action is taken. }\end{array}$ \\
\hline 1 & $\begin{array}{l}\text { "Imminent" failure Failed conditions. Major deterioration or section loss } \\
\text { present in critical structural components or obvious vertical or horizontal } \\
\text { movement affecting structural stability. Bridge is closed to traffic but } \\
\text { corrective action may put it back in light service. }\end{array}$ \\
\hline 0 & Failed conditions. Out of service and beyond corrective action. \\
\hline
\end{tabular}




\section{DETERMINATION OF LOAD-BEARING CAPACITY}

Contemporarily of the Load rating of bridges include the Load and Resistance Factor (LRFR) method, the Load Factor (LFR) method and the Allowable Stress (ASR) method. The rating procedures presented for the LRFR method recognize a balance between safety and economics [87]. In most cases, a lower target reliability than design has been chosen for load rating at the strength limit state. The LRFD calibration reported a target LRFD reliability index $\beta$ of 3.5. The LRFR procedures adopt a reduced target reliability index of approximately 2.5 calibrated to past AASHTO operating level load rating. The methodology for the load and resistance factor rating of bridges is comprised of three distinct procedures: (i) design load rating, (ii) legal load rating, and (iii) permit load rating. The results of each procedure serve specific uses and also guide the need for further evaluations to verify bridge safety or serviceability.

The lack of reinforcement must be compensated [17]. It is necessary when the deflections of the elements exposed to buckling are larger than 1/150 of the span or wide cracks have been detected. Failure state for the deflection higher than Lo/50 $[17,5]$, where Lo is span of beam.

The Condition factor $F_{C}$ (which has a value between 0 and 1 and which can be estimated by engineering judgement of deterioration) is introduced for the damaged structure [17b]. The assessment resistance $\left(R_{A}\right.$ - function of quotient of characteristic or nominal strength of the material and partial safety material factor) should be greater than the assessment external loading and action $\left(S_{A}\right)$ :

$$
\overline{R_{A}}=\text { function }\left|\frac{f_{k}}{\gamma_{m}}\right|=F_{C} \cdot R_{A} \geq S_{A}=\gamma_{f 3} \mid \text { effects of }\left(\gamma_{F L} \cdot Q_{K}\right) \mid,
$$

where the following are: $f_{k}$ is the characteristic or nominal strength of material, $\gamma_{m}$ - partial material factor; $\gamma_{f 3}$ - factor that takes into account inaccurate assessment of the effects of loading, unforeseen stress distribution in the structure, and variations in dimensional accuracy, $\gamma_{F L}$ - partial factor on loads. The strength $R$ and load $S$ are function of time.

It has already been stressed that the evaluation of the state of a concrete structure, the programme of research works, its implementation and the programme of intervention measures largely depend on the subjective opinion of the expert team to whom the job is entrusted.

A load rating is a simplified measure of the capacity of an existing bridge to carry live load. It is calculated by first determining of total capacity of each

Engineering Sciences, LVII, 2020, No. 4 
member in terms of stress. Bridges are typically rated at two levels. The first level is for normal conditions. AASHTO calls this the Inventory rating. The other level is the maximum live load level a bridge can be expected to support at unfrequented intervals call the Operating rating [95].

The rating equation defined by AASHTO is:

$$
R F=\frac{C-A_{1} D}{A_{2} L(1+I)},
$$

where $R F$ is the rating factor for live load-carrying capacity, $C$ - capacity of element, $D$ - dead load effect of element, $L$ - live load effect of standard truck on element, $I$ - impact factor to be used with live load, $A_{1}$ - factor for dead load depending on method of calculation, $A_{2}$ - factor for live load depending on method of calculation.

For the service load method, $A_{1}=A_{2}=1.0$. The difference between normal and maximum rating levels is made by changing the stress allowed in the element capacity $C$. The method can be applied for a load in one lane and for a span up to $61 \mathrm{~m}$. A detailed analysis is shown in [95].

Developing a custom-made BMS is a long-term commitment involving initial investment, life-cycle maintenance costs, and state-of-the-art expertise.

After assessing the condition of the elements and the structures, it is necessary to make a decision in the maintenance plan on the adequate time/deadline for the execution of works. This is achieved by introducing grading - ratings based on assessment criteria, which consider the probability of failure. Four methods are used for this purpose: deterministic; the method of target reliability and the method of optimizing the total cost of service life. However, the best solution is to intervene immediately after a property deteriorates below the desired level with minor but more frequent interventions. Larger but less frequent interventions are caused by the properties deteriorating to a minimum.

There is accumulation of waste in less accessible places, as well as of fine sludge, etc. the waste is concentrated in expansion joints, drainage systems and on all surfaces where water from the road reaches. The chemical content of the waste material causes damage to the bridge elements. This condition needs to be overcome by routine maintenance work.

In Australia, a model of predicting the condition of the elements used in BMS was described in [106]. The system was developed in the United States and it is based on the use of the Markov chain's continuous time to manage concrete bridges. The highest probability is used to estimate the deterioration parameters and the initial corrosion time. The Monte Carlo simulation method 
was used for the simulation when selecting the bridge on which renovation will be performed.

\section{MAINTENANCE OF CONCRETE BRIDGES}

The main goals of the management system are: formation of complete, easily accessible and up-to-date documentation on bridges. To this end, it is necessary to plan the monitoring and maintenance of bridges in an appropriate manner. The functionality and reliability of bridges are monitored with the optimization of all activities in technical and economic terms. Based on the data for the network, bridges are also ranked in order to make decisions on the type and scope of necessary works on the facility, bearing in mind the limitation of financial resources. The highest priority is given to the works, whose postponement can cause the largest increase in costs, and an important element is the importance of the road, or problems related to the load-bearing capacity of the bridge.

In NCHRP Synthesis 327 [9] and AASHTO Maintenance Manual [10] can find a list of the following definitions: Maintenance - the technical aspect of the upkeep of the bridges; it is preventive in nature. Maintenance is the work required to keep a bridge in its present condition and to control potential future deterioration. The works do not considerably alter the physical structure and disrupt functioning. Renovation refers to major interventions on the elements with the goal of removing defects and damage. It restores the original bearing capacity and/or ductility properties which are defined as nominal. Rehabilitation is the process of restoring the bridge to its original service level. Repair is the technical aspect of rehabilitation; action taken to correct damage or deterioration on a structure or element to restore it to its original condition. The definitions have the following significant implications: Maintenance does not improve condition ratings; Rehabilitation and repair do not match identically the "original condition".

In another paper we can find comparative analysis of BMSs in different countries as in $[3 \div 7]$, and for inspection methodologies and evaluation criteria [8]. The widest considerations on the contents and application of BMS in the United States and in the world are given in Yanev's book [85], which can serve for a deeper understanding of the complex problems related to BMS.

Short definition of a bridge management system in [87] is an effective tool in allocating limited resources to bridge related activities. If the deteriorate bridge repair works will be more expansive than maintenance work [6], within BMS in Iran. The database is basically a sore containing all of the information 
about the bridges in a particular network. It contains a technical nature as well as administrative and financial information. Figure 3 shows how BMS is organized in form of the guideline, as well an overview of the COWI-NMS modules.

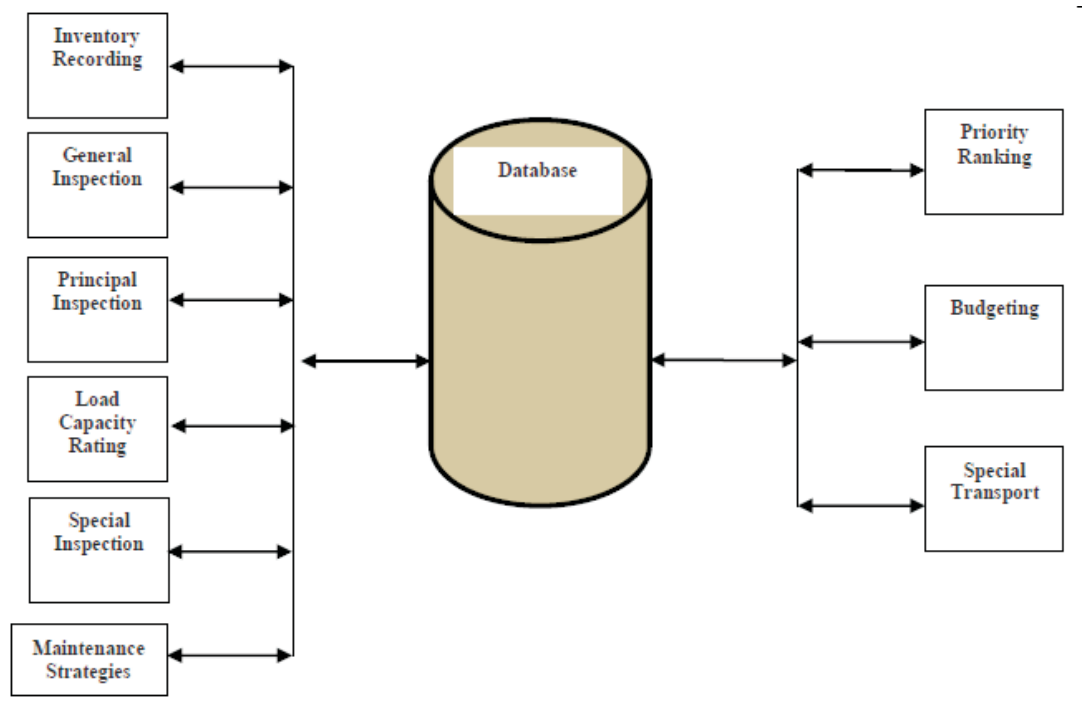

Fig. 3. Overview of the COWI-BMS modules, after [6]

During operation, the upper surface of the deck is exposed to permanent and traffic loads, the effects of temperature, frost, chemicals and more. The use of de-icing salt is very harmful and has an aggressive effect on concrete and reinforcement, especially on road decks of road bridges. Particularly sensitive places are in the vicinity of expansion joints, drainage channels, drains, as well as in places where railing and traffic signs are anchored to the pavement. This can be mitigated by making a sufficiently thick, compact and impermeable protective layer of concrete and a quality waterproofing and drainage system. Good pavement and waterproofing can mitigate this effect. For this reason it is important to maintain the road decks of road bridges in order to increase their durability.

All methods consider the probability of failure in a certain way. The application of the deterministic method dates back to the eighties and bridges of small spans (spans up to $50 \mathrm{~m}$ ) were tested with it. However, a deterministic approach based on simple engineering estimation gives approximately the same results as other methods [65, 78]. 
The assessment of condition is the basis for making a decision on the type of work that needs to be performed (maintenance, repair or reconstruction) or these works are not necessary [107].

Maintenance works can be routine and investment (capital). Routine Maintenance Works are carried out at regular intervals as permanent activity and include minor activities such as:

- Cleaning of the drainage system, expansion joints;

- Repair of impact damage to bridge parapets/safety barriers;

- Sweeping of carriageway and pedestrian pathways;

- Cutting of vegetation growth on Revetments/Embankments adjacent to the bridge and removing driftwood from the upstream side of pillars;

- Repair of concrete surfaces and protective layers of concrete,

- Maintenance of bearings;

- Protection of reinforcement from corrosion;

- Works to be carried out at appropriate times (not too often or too late). Similar provisions and recommendations are presented in [87] and the EIRSPAN Routine Maintenance Module.

Capital maintenance requires more resources and includes replacement of degraded parts of the bridge or repair of major damage. This entails utilization of special technical equipment and appropriate preparation for works execution. The following works are executed:

- Replacement of bearings;

- Replacement of expansion joints;

- Replacement of large parts of the railing or entire railing;

- Renovation of the bridge insulation;

- Major structural repairs.

Repair of damaged concrete in case of corrosion is very important. Defective concrete should be cut ( $\min 50 \mathrm{~mm}$ ) outside the loose concrete layer and all loose material should be removed. Exposed reinforcement should be thoroughly cleaned of the rust with brushes, sandblasting, chemical solutions, etc. It is to be replaced with new protective cement mortars or a suitable epoxy coating before further treatment.

In the USA, the basis for individual bridges is the design management level, and other aspects refer to the set of bridges at the network level. At the design level, the condition of the bridge, load-bearing capacity and the results of non-destructive tests that affect the determination of the time and type of maintenance work are considered. The parameters of other bridges must be taken into account in the set of bridges. The reason is that the budget is limited, so ranking in terms of priorities must be established, and the flow 
of traffic affects maintenance work and execution time. During the execution of these works, such technology is chosen which will reduce the disruption of traffic on the bridge to a minimum. Of particular importance is the possibility of access to inaccessible places, so in the United States, special stairs are used, and special galleries are used for observation.

Functional service life is the expected time of usage determined through mathematical and statistical data on the real service life [100]. Real service life must not be shorter than normative life. The time between overhauls besides repair planning also serves for the assessment of organization efficiency of technical exploitation (management).

In [83] the following basic maintenance strategies are given for structures:

1. Basic maintenance through repairs after damage has been noticed. Corrective maintenance or Failure-based Maintenance (FBM): maintenance actions are undertaken after failure has been noticed.

2. Repairs after the structure have been used for some time. Use-based Maintenance (UBM): maintenance actions are taken after a certain use (time, distance, load history, etc.).

3. Interventions according to the state of more significant components after some unexpected circumstances or due to the exceeding of some deviation limits noticed during regular inspections. Condition-based Maintenance $(\mathrm{CBM})$ : maintenance actions are taken after a certain, unacceptable, condition limit is exceeded and noticed (by inspection, monitoring, performance, etc.).

The first method is applied to all parts and components of the building. The second can be applied if the frequency of damage during time is known, which can result in a preventive maintenance as in the third method, which can only be applied if conditions are measurable. In practice these strategies - methods are not strictly divided. Small damage or lower performances should be taken as a sign that on the components of the building it should be intervened without waiting for bigger damage to occur.

Maintenance according to the state relies on the monitoring of technical components in order to define their state, and establish an adequate diagnosis. This method is suitable for components for which it is possible to define the state really. Besides it is necessary to establish criteria for the assessment of serviceability limits for certain parts. For that purpose procedures are used based on the techno-economic criteria and experience.

Sometimes the structure is viewed as a technical system hence the consequences of function failures for some components are studied. For particular components probability functions on behaviour through time can be used. 
The first method can only be used in case of a small risk. The risk is defined as a product of damage consequences and probability for their occurrence. With the aging of the structure the risk grows, therefore the first strategy is transformed into preventive maintenance.

To take suitable measures in maintenance, i.e. to determine its strategy, it is necessary to anticipate as accurately as possible the type of the aging mechanism, which means the degradation of certain components.

\section{Preventive Maintenance [12] New York and AASHTO}

Throughout the life of a bridge structure there are anticipated activities that are necessary to realize the full potential of the capital bridge investment. The goal is to maintain the bridge asset at the lowest cost over the life of the structure. Historically it has been found that a strong preventive effort is the most cost effective approach.

Preventive maintenance activities can be classified into two groups -1 . scheduled and 2. response.

1. Scheduled interval basis include:

- cleaning decks, seats, caps, and salt splash zones;

- cleaning bridge drainage systems;

- cleaning and lubricating expansion-bearing assemblies; and

- sealing concrete deck or substructure elements.

2. Response - Corrective or Minor Repairs are activities that are performed on an as-needed basis include:

- resealing expansion joints;

- painting structural steel members

- removing debris from waterway channels;

- replacing wearing surfaces;

- extending or enlarging deck drains.

Preventive maintenance is typically applied to bridge elements on structures with significant remaining service life. The concept of preventive bridge maintenance suggests that many relatively small repairs and activities are performed to keep the bridge in good condition and thereby avoid large expenses in major rehabilitation or replacement.

It is shown that the exclusive use of the concept of corrective maintenance is not suitable. The modern maintenance concept is based on the probability approach, i.e. registration of damage and its frequency determining time and intervention level needed. Thus the introduction of preventive and combined maintenance is suggested.

Engineering Sciences, LVII, 2020, No. 4 
The state of the structure must be assessed in all maintenance stages. A timely detection of damage enables a cost-effective rehabilitation. For the entire maintenance organization it is important to anticipate a type of the degradation process of the structure and its components. Care must be taken of external and internal degradation factors. The entire management economy of structures requires an adequately chosen maintenance strategy. In most cases it is achieved by combining regular and preventive maintenance.

The overall costs of the bridge have to include also the cost of maintenance and major interventions so that the structure would retain the service properties $[25,82]$.

The aim of the management organisation is to provide optimal economy for all investments during a certain period of time. The concept of management of structures should be formed in such a way to provide the uninterrupted use of the structure within a time interval, with minimal investments in its behaviour monitoring and repairs. To achieve this, it is necessary to define requirements regarding the state of the structure and its components.

In order to provide the mentioned properties it is necessary to pay due attention not only during the design and construction period of a structure, but during the use and maintenance period as well. Therefore the maintenance suitability is an important feature of the structure.

\section{COMPARISON OF SOME ELEMENT OF BMS}

Most frequently bridges and overpasses are classified according to their span and statical system. At a span of $2.0 \mathrm{~m}$ the inspection mandate applies, as this is treated as a bridge. The British introduce the least value of the span of $1.80 \mathrm{~m}$ and the South Africa of $6.0 \mathrm{~m}$. Several detailed descriptions of defects with their impact on the bridge function, and definition of bridge components are presented, also [9].

Comparative data of inspections and supervision by inspection program in USA, S. Africa, U.K. and six European countries are summarized in Table 7 . For the same countries data of inspection and maintenance and repair recommendation are summarised in Table 8.

In addition to the U.K. and the mentioned manual [13], bridge inspection is most often regulated at the state level, including the USA. An example is the Massachusetts Department of Transportation (DOT) manual [16], which provides instructions for writing reports in addition to field inspection and data recording instructions. Similar manuals are used in New York, Georgia, Florida, and other states, and the federal agency has synthesized and published 

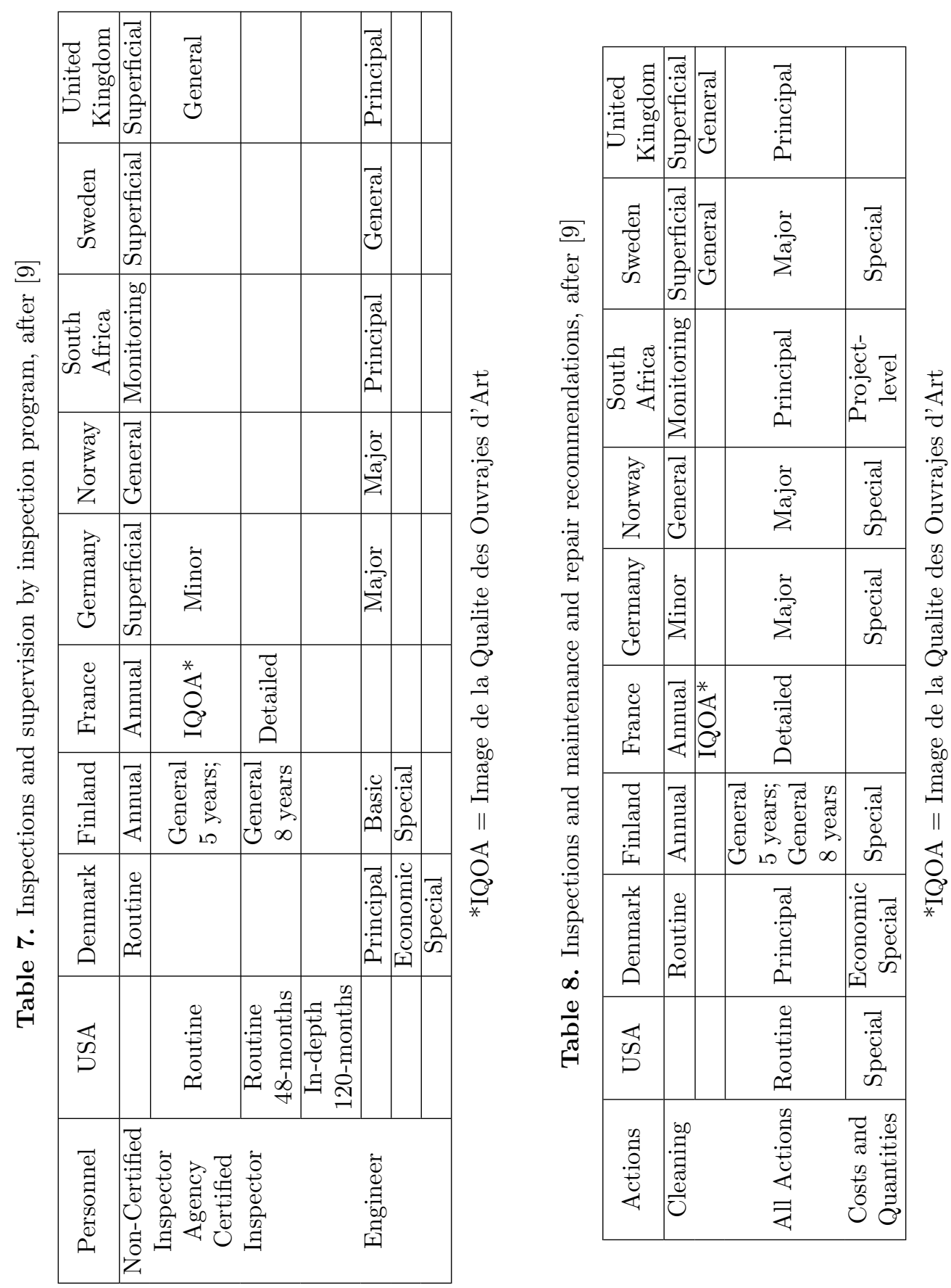

Engineering Sciences, LVII, 2020, No. 4 
the manual. Maintenance inspection and rating were analyzed in the BE Handbook [9]. Inspection for maintenance and rating system in BE Handbook [15] are analysed. Supplementing inspections, one chapter is dedicated to one of the newer methods of Bridge Health Monitoring (BHM) [14].

The problems related to BMS are most extensively considered in the Manual [3], with chapters devoted to deterioration, investigation, monitoring and assessment. In addition, the condition prediction of existing bridges is important, as well as forming the bridge deterioration model, which is the subject matter of $[105,106,66]$. The development of BMS based on Building Information Modelling is analyzed in [30].

In addition to the systems, software is used in some European countries and listed in Tables $1 ; 7 ; 8 ; 9$. Table 5 shows the 21 BM Systems used worldwide. Some countries use more systems such as Canada and the United States.

The most significant application of contemporary BMSs can be found in the USA. The principal BMS used in US is Pontis, developed in the early 1990s for the FHWA and it became an AASHTO product in 1994. It records, stores and directs data on the inventory and inspections of the bridge, simulating the situation and proposing actions, developing a preservation policy and developing an overall bridge management program. The system allows representation of bridge as a set of structural elements, where each element is reported based on its condition. The Bridge system, developed in 1985 by the National Cooperative Highway Research Program (NCHRP), has a capability similar to the Points.

A recent European experience is the TISBO Infrastructure Maintenance Management System, developed in Netherland. It is a system that integrates inspection registration and maintenance management. A number of research projects have been established by the European Commission and some published guidelines dealt with the assessment of existing bridges in Europe, BRIME (2001), COST345 (2004), SAMARAS (2005) and sustainable bridges (2006).

A recent comparative analysis of the practice of inspection of bridges in China, USA, Japan and South Korea was presented in [10]. Standards, manuals and guides used in the four countries are presented and compared. Inspection types, intervals, reporting systems, bridge condition ratings are also presented and compared. Based on this analysis the authors conclude that the four countries show similarities in the overall process of bridge inspection practices and bridge management programs such as the use of a BMS in quality control. 
Table 9. Twenty-one BMS used worldwide, after [30]

\begin{tabular}{|c|c|c|c|c|}
\hline No. & Country & System name & Abbreviation & First version \\
\hline 1 & Canada & Ontario BMS & OBMS & 2002 \\
\hline 2 & Canada & Quebec BMS & QBMS & 2008 \\
\hline 3 & Canada & EBMS & EBMS & 2006 \\
\hline 4 & Canada & PEIBMS & PEIBMS & 2006 \\
\hline 5 & Denmark & DANBRO BMS & DANBRO & 1975 \\
\hline 6 & Finland & The Finish BMS & FBMS & 1990 \\
\hline 7 & Germany & $\begin{array}{l}\text { Bauwerk Management Sys- } \\
\text { tem }\end{array}$ & GBMS & $\mathrm{N} / \mathrm{A}$ \\
\hline 8 & Ireland & Eirspan & Eirspan & 2001 \\
\hline 9 & Italy & $\begin{array}{lll}\text { Autonomous } & \text { Province } & \text { of } \\
\text { Trento BMS } & \end{array}$ & APTBMS & 2004 \\
\hline 10 & Japan & $\begin{array}{l}\text { Regional Planning Institute } \\
\text { of Osaka BMS }\end{array}$ & RPIBMS & 2006 \\
\hline 11 & Korea & $\begin{array}{l}\text { Korea Road Maintenance } \\
\text { Business System }\end{array}$ & KRBMS & 2003 \\
\hline 12 & Latvia & Lat Brutus & Lat Brutus & 2002 \\
\hline 13 & Netherland & DISK & DISK & 1985 \\
\hline 14 & Poland & SMOK & SMOK & 1997 \\
\hline 15 & Poland & SZOK & SZOK & 2001 \\
\hline 16 & Spain & SGP & SGP & 2005 \\
\hline 17 & Sweden & $\begin{array}{l}\text { Bridge and Tunnel Manage- } \\
\text { ment System }\end{array}$ & BaTMan & 1987 \\
\hline 18 & Switzerland & KUBA & KUBA & 1991 \\
\hline 19 & USA & Bridgit & Bridgit & 1993 \\
\hline 20 & USA & Pontis & Pontis & 1992 \\
\hline 21 & Vietnam & Bridgemann & Bridgemann & 2001 \\
\hline
\end{tabular}

COST Action TU 1406 defines bridge performance indicators: reliability, availability, maintainability, safety, security, health, environment, economics, and politics [108]. The terminology criteria should be related to the performance aspect and sub-criteria [16]: Safety related from unacceptable risk in terms of injure to people. Security related to the safety of a system regarding to vandalism and destructive human behaviour. This problem can be solved by analysis of bridge robustness. Economics addresses the relationship between cost and value, and politics concerning political-administrative and social requirements. 


\section{FINAL REMARKS AND CONCLUSIONS}

The presented comparisons reveal differences and similarities between the provisions of individual countries, which can be used in the further development of BMS in Serbia, Bulgaria and the countries of our region. It should be borne in mind that:

- Regular monitoring of the condition of bridge components in the BMS enables timely interventions, which ensures greater durability and serviceability of bridges. This is achieved by optimizing maintenance costs; and

- The proposed BMS should include life-cycle models, tools for quality management, and cost-benefit optimization models related to bridges, which would help decision-making institutions that manage traffic and bridges. BMS has become easily accessible to inspectors and decision makers thanks to advances in information technology [2];

- Science advance by deterministic and probabilistic reasoning and bridge management should take full advantage of both, in a balance suitable for the specific needs of every location.

The procedure includes two levels of analysis: the project level (considers every single bridge), and the network level (considering inserted in a global road network). The aim is to establish priority of intervention, according to the evaluation of bridge condition based on inspection and quantitative rating. Bridge evaluation starts with visual inspection. The bridge network maintenance could be improved by defining deterioration trends with performancebased life cycle models. An adequate bridge management methodology is needed, which includes planning the costs of maintenance or rehabilitation of structures.

Modern BMS includes a bridge database, an inspection system, a condition evaluation, a lifetime prediction of the future conditions of the structure and maintenance system planning. Modern BMSs have the following modules: (i) Database/Inventory; (ii) Inspection; (iii) Maintenance; (iv) Life Cycle Cost [49]; (v) Prediction model (Deterioration prediction in remain service life for existing bridges) $[72,106]$. Most difficulties occur while developing deterioration models because transportation agencies have no reliable data about defects and rates of aging and damage. They are specific to every state. Bridge vulnerability analysis has also rescently been introduced [109].

The goal of regular inspections is to directly control the condition of the building and maintain traffic safety at satisfactory level. However, management is based on economic analysis and ranking by priorities because it is necessary to use the available funds in the most efficient way, since the budget 
in all countries is limited. The concept of structural management requires that minimal investments in behaviour monitoring and repair ensure an uninterrupted use of the structure in a certain time interval. When considering maintenance strategies there are two extreme positions: to carry out maintenance as soon as inspections identify the need, and to carry out maintenance only on safety grounds. The first requires more frequent repairs and traffic congestion, and the second requires balancing costs due to the shorter bridge life in order to avoid higher maintenance costs [3].

Maintenance is to ensure that the bridge receives and safely supports a certain traffic load across the obstacle with certainty during the operational period. Maintenance of bridges in terms of repairs, strengthening, or replacement of individual elements in the building, is performed in accordance with the plans and programs. Assessment of the load bearing capacity and general condition of the structures, as well as assessment of the conditions of use within the changed environmental conditions are of high importance.

In the USA, in addition to the synthesis of documents from the states, a comparative analysis of European and some other countries [9] was conducted. We estimate that Serbia and Bulgaria, with certain modifications of the existing BMS and following the example of some of the European countries, would contribute to more economical management of bridges. Also, it is recommended to introduce a contemporary method of monitoring the condition of the elements and bridges - Structural Health Monitoring (SHM) [110].

It is recommended to design integral bridges, without expansion joints, and using an integral approach, comprising the complete life cycle (from the beginning of designing to the removal of the structure) because this includes the structural management $[5,7]$.

\section{ACKNOWLEDGEMENTS}

The research described in this paper was financially supported by the Ministry of Education and Sciences of Serbia within the Project: "A comprehensive approach to improvement of interdisciplinary researches in construction education and science" (University of Novi Sad, FTS, Department of Civil Engineering and Geodesy). This support is gratefully acknowledged (R. Folić).

The authors would like to express their great appreciation to Professor B. Yanev, Columbia University USA, for his valuable and constructive suggestions that contributed to the improvement of this paper.

Engineering Sciences, LVII, 2020, No. 4 


\section{REFERENCES}

[1] EN 1990:2002: Basis of Structural Design, CEN, 2002 (Translation Grapevinski Faculty, Belgrade, 2006).

[2] Y. JeAng, et al., Bridge Inspection Practices and Bridge Management Programs in China, Japan, Korea and U.S., J. of Integrity and Maintenance (2018) 3 (2) 126-135.

[3] ICE Manual Bridge Engineering, Bridge Management (P. R. Vassie and C. Arya) 691-613; Deterioration, Investigation, Monitoring and Assessment (C. Abdunur) 615-657; Inspection and Assessment (I. Kennedy Reid) 659-693; Protection (M. Mulneron); Repair, Strengthening and Replacement (J. Derby) 695-728, $2^{\text {nd }}$ Ed. (Eds G. Parke, N. Hewson, T. Telford), London (2008).

[4] C. Dullah, et al., Bridge Management System in Sabah, Int. J. of Engineering Research \& Technology (2014) 3 (8) 976-980.

[5] R. Folić, Comparative Analysis of BMS, J. Izgradnja, Belgrade (2019) 73 (11-12) 455-488 (in Serbian).

[6] M. Gholami, et al., Assessment of Bridge Management System in Iran, Precedia Engineering (2013) 54 573-583.

[7] K. Gkoumas, et al., Publications Office of the European Union: A European Perspective Based on the Transport Research and Innovation Monitoring and Information System (TRIMIS) (2019).

[8] L. Hsien-Ke, Comparison of Bridge Inspection Methodologies and Evaluation Criteria in Taiwan and Foreign Practices, in: $34^{\text {th }}$ Int. Symp. on Automation and Robotics in Constr., 2017, pp. 1-8.

[9] National Cooperative Highway Research Program (NCHRP) Synthesis 375, Bridge Inspection Practices - A Synthesis of Highway Practice, Transportation Research Board (2007).

[10] AASHTO (American Association of State Highway and Transportation Officials) (2011): (a) Bridge Element Inspection; Ch. 4. Bridge Inspection Reporting; Manual Bridge Evaluation (2018); (b) FHWA (2012): Bridge Inspector's Manual, Section 2.2-BM (Concrete), Instr. M. Rossow, PDH Center; Reference Manual (2012).

[11] Bridge Inspection and Maintenance, Ch. 3 (2009), Structural Rehabilitation Manual (1990), Ministry of Transportation, Ontario.

[12] Bridge Inspection Manual, New York State Dep. of Transportation Office of Structures, January (2016).

[13] Bridge Inspector's Handbook, Overseas Road Note, Crowthorne, England (2008) 2.

[14] Bridge Engineering Handbook - Construction and Maintenance (Eds Wai-Fah Chen and L. Duan) (Ch. 10: Bridge Health Monitoring, D. Frangopol \& S. Kim; Ch. 13: Bridge Inspection, J. E. Copelan) (2014). 
[15] Bridge Engineering Handbook, Ch. 49: Maintenance Inspection and Rating (M. Vinayagamoorthy) and 50: Strengthening and Rehabilitation (F. W, Klaiber and T. J. Wip) (Eds Wai-Fah Chen and L. Duan), CCR Press, Boca Raton (2002).

[16] Bridge Inspection Handbook, Ch. 4: Field Inspection, Data Collecting, Report Writing and Report Review, Mass, DOT, 14.05 (2018).

[17] a) CEB, Bulletin D'Information (BI): Assessment of CS and Redesign, No. 162 (1983); b) Diagnosis and Assessment of CS BI No. 192 (1989).

[18] FHWA, Bridge Inspector's Manual, Section 2.2-BM (Concrete), Instr. M. Rossow, PDH Center; Reference Manual, 2012.

[19] ACI Committee 201: Guide for Making a Condition Survey of Concrete in Service (2019); Verification of Structural Adequacy by D. Kaminetzky, SP-85-6; ACI 364.1R-07.

[20] ACI Guide for Repair of Concrete Bridge Superstructures (1980): ACI 546.1R80.

[21] ACI Guide for Evaluation of Concrete Structures Prior to Rehabilitation (2007); ACI 546.1R-14: Guide for Repair of Concrete Bridge Superstructures; ACI 345.1R-92 Routine Maintenance of Concrete Bridge; Structural Repair Corrosion Damage and Control-Seminar Course Manual (SCM-8), Concrete Repair and Restoration, Compilation No. 5 (1990).

[22] ACI 224R-07: Causes, Evaluation and Repair of Cracks in CS.

[23] M. A. Khan, Bridge and Highway Structure Rehabilitation and Repair, McGraw Hill, New York (2010).

[24] M. Raupach and T. Buttner, Concrete Repair to EN 1504 - Diagnosis, Design, Principles and Practice, CCR Press (1997).

[25] P. H. Emmons, Concrete Repair and Maintenance, R. S. (1994).

[26] Florida Department of Transportation, Bridge Management System - Coding Guide (2018).

[27] Rulebook on Technical Standards for Operation and Regular Maintenance of Bridges (1992) 20, Bridge Inspection Manual, JP Roads of Serbia, Editon TWINNING Publ., Belgrade (2009) (in Serbian).

[28] A. H. ElkhaleK, et al. Framework for Bridges Maintenance in Egypt, Int. Journal of Engineering Research and Application (2016) 6 (1, part 5) 48-54.

[29] F. Bortot, et al., A Bridge Management Strategy Based on Future Reliability and Semi-Markov Deterioration Models, $3^{\text {th }}$ International ASRANet Colloquium, Glasgow, 10-12 July, 2006.

[30] O. Kanesel, Proposal for Libya's Bridge Management System (BMS), Journal of Engineering Research, Tripoli (2014) 20.

[31] S. Helland, Performance-Based Service Life Design in the 2021 Version of the European Concrete Standards - Ambitions and Challenges (Keynote Lectures), Proceedings of the fib Symposium, Cape Town, South Africa, 2016, pp. 32-41. 
[32] B. Mahut and R. J. Woodward, Comparison of Bridge Management Practice in England and France (2018), https://trl.co.uk/sites/default/files/PAINF-4496-05.pdf (retrieved September 2019).

[33] CIRCULAR, Transportation Research, Number E-C 1218, International Bridge and Structure Management, $10^{\text {th }}$ Int. Conf., Bufalo New York, October 20-22, 2008.

[34] Y. Xia And P. Wang, Condition Assessment and Maintenance Strategies for Bridges at Individual \& Network Level, in: $40^{\text {th }}$ IABSE Symposium, Nantes, France, 19-21 September, 2018, pp. 14-38.

[35] R. J. WoodwaArd, et al., BRIME, Project, March (2001).

[36] C. Pellegrini, et al., A Simplified Management Procedure for Bridge Network Maintenance, Structure and Infrastructure Engineering (2011) 7 (5) 341-351.

[37] P. D. Thompson, et al., The Pontis Bridge Management System, Structural Engineering International, IABSE (1998) 8 (4) 303-308.

[38] Z. Marzaei, et al., The IABMAS Bridge Management Committee Overview of Existing BMSs (2012).

[39] Bridge Preservation Guide - Maintaining a Resilient Infrastructure, USA, FHA, Spring (2018).

[40] R. Folić And D. Partov, Comparative Analysis of Some BMS, Building Materials and Structures (2020) 63 (3) 21-35.

[41] T. Siemes, Overview of the Service Life and Maintenance Problem Probabilistic Design, DRMC, 2002, 3, Paper 260, pp. 1-10.

[42] S. K. Verma, et al., Estimating Residual Service Life of Deteriorated RC Structures, Amer. J. of Civil Eng. and Architecture (2013) 1 (5) 92-96.

[43] F. Biodini and D. M. Frangopol, Life-Cycle Performance of Deteriorating Structural Systems under Uncertainty. Review, J. Struct. Eng. (2016) 142 (9) F4016001.

[44] H. Elbehairy, Bridge Management System with Integrated Life Cycle Cost Optimization, Ph. D. Thesis, Waterloo, Canada (2007).

[45] fib Bulletin No. 34, Model Code for Service Life Design, Lausanne, Switzerland (2006) 116, ISBN 978-2-88394-074-1.

[46] fib Bulletin No. 71, Integrated Life Cycle Assessment of Concrete Structures, State-of-art report, Lausanne, Switzerland (2013), ISBN 978-2-88394-111-3.

[47] ISO 16204, Durability - Service Life Design of Concrete Structures, International Organization for Standardisation, Geneva (2012).

[48] J. L. Jansen, Life Cycle Costs - Any use? in: $37^{\text {th }}$ IABSE Symp. Madrid, Rep. 2014, 102, pp. 2284-2892.

[49] A. SarJa, Integrated Life Cycle Design of Structures, Spoon Press, London (2002).

[50] A. Saviotri, Bridge Assessment, Management and Life Cycle Analysis, Modern Applied Science (2014) 8 (3) 167-180. 
[51] N. M. Okasha and D. M. Frangopol, Computational Platform for the Integrated Life-Cycle Management of Highway Bridges, Eng. Structures (2011) $332145-2149$.

[52] M. Chryssanthopoulos and G. Sterritt, Integration of Deterioration Modelling and Reliability Assessment for Reinforced Concrete Bridge Structures, University of Surrey, UK (2003).

[53] R. Folić, M. Ćosić And B. Folić, Deciding the Order of Interventions on the Structure of RC Bridges for Earthquake Conditions, in: Proc. $16^{\text {th }}$ International Symposium: Contemporary Structures - Sustainable Development, MASE 16, Book of Abstracts, SE-5, 1-3 October, 2015, pp. 157-158; Pros. pp. 698-707, ISBN 608-4510-24-8.

[54] P. Thompson, et al., Multi-Objective Optimization for Bridge Management Systems, NCHRP Report 590, 25 September, 2017.

[55] J. M. Van NoortwiJk and D. M. Frangopol, Two Probabilistic LifeCycle Maintenance Models for Deteriorating Civil Infrastructure, Probabilistic Engineering Mechanics (2004) 19 (4) 345-359.

[56] M. Zanini, et al., State of Research on Performance Indicators for Bridge Quality Control and Management, Frontiers in Built Environment, March (2019) 5 Article 22.

[57] fib Bulletin No. 22, Monitoring and Safety Evaluation of Existing Concrete Structures, Lausanne, Switzerland (2003), ISBN 978-2-88394-062-8.

[58] fib Bulletin No. 17, Management, Maintenance and Strengthening of Concrete Structures, Lausanne, Switzerland (2002) 174, ISBN 978-2-88394-057-4.

[59] fib Bulletin No. 44, Concrete Structures Management: Guide to Ownership and Good Practice, Lausanne, Switzerland (2008), ISBN 978-2-88394-084-0.

[60] Next Generation Bridge Management Tools and Inspection, Final Report (Bektas, B. A), Minnesota DOT (2016).

[61] D. Zonta, et al., A Reliability - Based Bridge Management Concept, Structure and Infrastructure Engineering, September (2007) 3 (3) 215-235.

[62] I. Zambon, et al., Condition Prediction of Existing Concrete Bridges as a Combination of Visual Inspection and Analytical Models of Deterioration, Applied Sciences (2019) 9 (1) 148.

[63] A. O'Connor and I. Enevoldsen, Probability-Based Assessment Bridges and-European Experience, ICE, J. of Bridge Eng. (2007/8) 160 (3) 129-137.

[64] O. Tarek and N. L. Monscef, Condition Assessment of Reinforced Concrete Bridges: Current Practice and Research Challenges, Infrastrucrures (2018) 3 36, doi:10.3390/infrastructures3030036.

[65] B. YAnev, Probability and Determinism in Bridge Management, Building Materials and Structures (2019) 62 (2) 3-13.

[66] H. Zhang, The Economy of Preventive Maintenance of Concrete Bridges Due to Corrosion, Syracuse University (2016). 
[67] R. Folić, et al., Earthquake Dame to RC Bridges and Review of Recommendation for Its Repair and Strengthening (ID 1594-Folic), in: Proc. $16^{\text {th }}$ European Bridge Conference (Ed. M. C. Forde), Edinburgh, Scotland, 23-25 June, 2015, p. 18, ISBN 0-947664-78-4

[68] M. G. Alexander, Service Life Design and Modelling of Concrete StructuresBackground, Developments, and Implementation, Revista ALCONPAT (2018) 8 (3) 224-245.

[69] CEB-FIP, Durable of Concrete Structures, Design Guide, T. Telford Ltd., London (1992).

[70] R. Folić, Some Methods of Protection, Repair and Strengthening of Concrete Bridges, in: Proceedings of the $6^{\text {th }}$ International Conference, Struga, 27-29 September, 2007, pp. 635-644.

[71] R. Folić, Durability Design of Concrete Structures - Part 1: Analysis Fundamentals, Facta Universitatis Series Architecture and Civil Engineering (2009) $7(1 / 09) 1-18$.

[72] R. Folić, D. Zenunović and N. Stojković, Durability and Service Life Prediction of Concrete Structures, in: Proc. $18^{\text {th }}$ International Symposium, MT-14, Macedonian Association of Structural Engineers, Ohrid, 2-5 October, 2019, pp. 280-291.

[73] fib Bulletins, International Federation for Structural Concrete, Model Code for Concrete Structures 2010, Lausanne Switzerland (2013).

[74] ISO 13823, General Principles on the Design of Structures for Durability, International Organization for Standardization, Geneva (2008).

[75] R. Folić, Bridges in Serbia, Handbook Bridge Engineering (Eds Wai-Fah C. and L. Duan), CRC Press, Taylor \& Francis, Boca Raton (2014) 587-647.

[76] S. Nanukuttan, et al., Methods of Assessing the Durability and Service Life of CS, Institute of Concrete Technology, in: Annual Technical Symposium, 6 April, 2017.

[77] D. Coronelli, Assessment and Repair of a Heavily-Corroded Reinforced Concrete Infrastructure, Structural Faults \& Repair (Ed. M. C. Forde), Edinburgh, 10-12 June, 2008.

[78] E. Figueiredo, et al., Condition Assessment of Bridges: Past, Present and Future, A Complementary Approach, Univers. Catolica Editiora (2013).

[79] T. Omar and M. L. Nehdi, Condition Assessment of Reinforced Concrete Bridges: Current Practice and Research Challenges, Infrastructures (2018) 3 (3) 36, DOI: 10.3390/infrastrucrures3030036.

[80] M. Rashidi and P. Gibson, A Methodology for Bridge Evaluation, J. of Civil Eng. and Archit. (2012) 6 (9) (Serial No. 58) 1149-1157.

[81] G. Roelfstra, et al. Condition Evolution in Bridge Management Systems and Corrosion - Induced Deterioration, ASCE-J. of Bridge Eng. (2004) May/June 268-277. 
[82] V. K. Raina, Concrete Bridge Practice - Construction, Maintenance and Rehabilitation, McGraw-Hill (1988).

[83] A. Toorn, The Maintenance of Civil Engineering Structure. Inspection and Maintenance Strategies, Heron (1994) 39 (2) Delft, 3-34.

[84] G. Nechevska-Cvetanovska and A. Roshi, Rehabilitation of RC Buildings Using Traditional and Innovative Materials, Building Materials and Structures (2019) 3 19-30.

[85] B. Yanev, Bridge Management, John Wiley \& Son, New Jersey (2007) 651.

[86] Georgia Department of Transport, Bridge Structure Maintenance and Rehabilitation Repair Manual (2012).

[87] Idaho Manual for Bridge Evaluation, Inspection and Load Rating (2020).

[88] IOWA DOT, Bridge Inspection Manual, January (2014).

[89] Framework for Improving Resilience of Bridge Design, Publication No. FHWAIF-11-016, U.S. Department of Transportation, Federal Highway Administration (2011).

[90] P. HaArdt, The German Approach to Bridge Management: from Reactive to Predictive Management Procedures, CIB 17704 (access September 2019).

[91] Bridge Maintenance and Repair Manual, VICROADS (2018), Web site: vicroads.vic.gov.au (Access September 2019).

[92] Main Roads Western Australia, Structural Inspection \& Information Management Policy (2013) Doc. No. 6706-01-202-Issue 16/08?2013, 25.

[93] A. Мryamoto and H. Asano, Development and Practical Application of Lifetime Management System for Prestressed Concrete Bridges, Civil Eng. Infrastructes J., December (2017) 50 (2) 395-410.

[94] FIP Reports: Inspection and Maintenance of Reinforced and Prestressed Concrete Structures, T. TELFORD LTD., London (1986), ISBN 978-0-7277-0261-6.

[95] J. L. Carrato, et al., Load Rating Criteria for Existing Concrete Bridges, ACI Concrete International, February (2020) 45-51.

[96] Transportation Research Board Executive Committee, Highway Research Program Report 301 (Moses, F. and Verma, D), Load Capacity Evaluation of Existing Bridges (1987).

[97] J. Stryk, Presentation on CERTAIN Workshop, Czech Republic, 21.5.2009,10.

[98] D. Bebić, Base of Bridge Data, The Institute of Road (2001) (in Serbian).

[99] World Road Association, Executive Summary: Estimation of Load Carrying Capacity of Bridges (2016).

[100] J. Bień And M. Salamak, Management of Bridge Structures - Challenges and Possibilities, in: Proceedings of the first IABSE Online Symposium Wroclaw (Eds J. Biec, et al.), 2020, pp. 8-31.

[101] P. HüтнwонL, et al., Integrating RC Bridge Defect Information into BIM Models, Journal of Computing in Civil Engineering (2018). 
[102] C. VAn, Development of a Bridge Management System Based on the Building Information Modeling Technology, MDPI Sustainability (2019) 114583 , doi:10.3390/su11174583.

[103] Y. Fujino, Bridge Maintenance, Renovation and Management - Research and Development of Governmental Program in Japan, Maintenance, Safety, Risk, Management and Life-Cycle Performance of Bridges (Eds N. Powers, D. Frangepol et al.), Taylor and Francis Group, 2018.

[104] K. D. Flaig, et al., The Development of UK Bridge Management Systems, in: Proc. Instn Engrs Transp., 2000, 141, Paper 11923, pp. 99-106.

[105] ACI Committee 365. 1R-42 (2017): Service-Life Prediction-State of the Art Report. ACI 201.12R-08 (2016): Guide to Durable Concrete, ACI.

[106] T. MAheswaran, et al., Deterioration Modelling and Prioritising of Reinforced Concrete Bridges for Maintenance, Australian Journal of Civil Eng. (2005) 1 $1-11$.

[107] M. Georgijević, Assessment of the Condition and Perspectives of Maintenance of Bridge Structures in the City of Niš, Building Materials and Structures (2017) 3 31-46 (in Serbian).

[108] J. C. MAtos, et al., COST Action TU 1406: Quality Specifications for Roadway Bridges, Standardization a European Level (BRIDGESPEC) - Performance Indicators, Conference Paper, November 2016.

[109] P. Marchaned, et al., SISMOA: A Simplified Method to Assess the Seismic Vulnerability of Existing Bridges, in: First Eur. Conf. on EE and Seismology, Geneva, 3-8 September, 2006, Pap. 150.

[110] S. Jamali, Assessment Load Carrying Capacity of Existing Bridge Using SHM Technology, Ph. D. Theses, Queensland University of Technology, School of CE and BES and Eng. Faculty (2019).

Received November 10, 2020 